\title{
Transcriptional targets for pituitary tumor-transforming gene-1
}

\author{
Yunguang Tong and Tamar Eigler \\ Department of Medicine, David Geffen School of Medicine at UCLA, Cedars-Sinai Research Institute, Davis Building, Room 3025, 8700 Beverly Boulevard, \\ Los Angeles, California 90048, USA \\ (Correspondence should be addressed to Y Tong; Email: yunguang.tong@ @shs.org)
}

\begin{abstract}
Pituitary tumor-transforming gene-1 (PTTG1) is a transforming gene first discovered in rat pituitary tumor cells. It possesses transcriptional activity and also has securin functions. Chromatin immunoprecipitation-on-chip study reveals that PTTG1 is a global transcription factor, which exerts its transcriptional activity either by directly binding to DNA or by interacting with proteins including PTTG1 binding factor, $\mathrm{p} 53, \mathrm{Sp} 1$, and upstream stimulatory factor 1. PTTG1 has several validated transcriptional targets that are involved in different cellular processes. PTTG1 activates c-Myc in NIH 3T3 cells, suggesting a role in cell transformation. PTTG1 induces fibroblast growth factor 2 expression and promotes tumor angiogenesis.It binds to and inhibits p53 transcriptional activity. PTTG1 activates cyclin D3 and represses p21 expression, indicating a role in cell cycle regulation and cell senescence. Here, we review PTTG1 transcriptional targets and their functions.
\end{abstract}

Journal of Molecular Endocrinology (2009) 43, 179-185

\section{Introduction}

Pituitary tumor-transforming gene-1 (PTTG1) was isolated from rat pituitary tumor cells in 1997 (Pei \& Melmed 1997), and subsequently identified as a vertebrate securin, which regulates sister-chromatid separation (Zou et al. 1999). PTTG1 has been reported to be overexpressed in a variety of tumors, including those from pituitary, breast, thyroid, ovarian, uterine, colon, and lung (Kakar 1999, Zhang et al. 1999a, Heaney et al. 2000, 2001, Shibata et al. 2002, Solbach et al. 2004, Chamaon et al. 2005, Tsai et al. 2005). PTTG1null mice exhibit testicular, splenic, pancreatic $\beta$-cell, and pituitary hypoplasia (Wang et al. 2001, 2003, Chesnokova et al. 2005). Disrupted PTTG1 results in insulinopenic diabetes in adult mice, with maleselective hyperglycemia (Wang et al. 2003). PTTG1 functions in cell replication (Zou et al. 1999), cell cycle control (Tong et al. 2007, 2008), DNA damage/repair (Romero et al. 2001), organ development, metabolism, cell transformation (Wang et al. 2001, 2003), and cell senescence (Chesnokova et al. 2007, 2008). Currently understood mechanisms of PTTG1 action include protein-protein regulation, paracrine/autocrine regulation, and transactivation. In this review, we describe PTTG1 transactivation functions, its role in neoplasis, protein structure, interaction proteins, and transcriptional targets.

Journal of Molecular Endocrinology (2009) 43, 179-185

0952-5041/09/043-179 (C) 2009 Society for Endocrinology Printed in Great Britain

\section{PTTG1 transcription function and cancer}

PTTG1 is considered as an oncogene because of its effects on tumor development and growth. PTTG1 is abundantly expressed in multiple cancer cells including: hematopoetic cells HL-60 and K562; colorectal adenocarcinoma cells SW480 (Lee et al. 1999); lung carcinoma cells A549; melanoma cells G361; hepatoma cells HepG2 (Lee et al. 1999); breast cancer cells MCF-7 (Kakar \& Jennes 1999); ovarian tumor cells such as SKOV3 (Kakar \& Jennes 1999); small cell lung cancer (SCLC); and non-SCLC (NSCLC; Honda et al. 2003, Rehfeld et al. 2006). Enhanced PTTG1 levels in tumor cells are confirmed in tumor tissue such as pituitary (Saez et al. 1999, Zhang et al. 1999a, Hunter et al. 2003, McCabe et al. 2003), colorectal (Heaney et al. 2000), esophageal cancer (Shibata et al. 2002), hepatocellular carcinoma (Cho-Rok et al. 2006), testicular, breast, ovarian (Puri et al. 2001), thyroid (Boelaert et al. 2003), and lung cancer (Rehfeld et al. 2006). High PTTG1 levels are correlated with higher tumor grade, invasiveness, and tumor vascularity (Heaney et al. 2000, Hlubek et al. 2006). PTTG1 demonstrates a transforming activity. Overexpressing PTTG1 in NIH 3T3 and HEK293 cells readily transforms the cells that form larger colonies in soft agar assay and bigger tumors in nude mice (Pei \& Melmed 1997, Zhang et al. 1999b). The knock-down of PTTG1 in H1299 lung cancer cells inhibits soft agar colony formation (Kakar \& Malik 2006).

DOI: 10.1677/JME-08-0176 Online version via http://www.endocrinology-journals.org 
Several mechanisms are proposed for PTTG1 role in cancer development. PTTG1 induces chromosome instability through binding to separase and regulating sister chromosome separation (Waizenegger et al. 2002). PTTG1 also induces genetic instability by inhibiting DNA damage repair through interfering with $\mathrm{Ku}$ heterodimer formation (Kim et al. 2007a). PTTG1, as a transcription factor, can directly and indirectly induce expression of genes that are involved in regulating tumorigenesis and cancer development. PTTG1 binds to c-Myc promoter and induces its expression in transfected NIH 3T3 cells (Pei 2001). PTTG1 induces bFGF in NIH 3T3, HEK293, NT-2, JEG-3, and MCF-7 cells through interacting with its binding factor (PBF; Chien \& Pei 2000, McCabe et al. 2002). PTTG1 also induces vascular endothelial growth factor (VEGF) and matrix metalloproteinase (MMP)2, which play an important role in tumor development and cancer metastasis (McCabe et al. 2002, Hunter et al. 2003, Malik \& Kakar 2006). PTTG1 interacts with transcription factors including p53, Sp1, and upstream stimulatory factor 1 (USF1), which may induce additional genes involved in tumorigenesis and cancer development (Pei 2001, Bernal et al. 2002, Tong et al. 2007). Several groups investigated the relation of PTTG1 transcription function and cell transforming activity. Zhang et al. (1999b) reported that mutation at PTTG1 C-terminal PXXP motif abolishes PTTG1 transforming activity. Boelaert et al. (2004) indicated that the mutation in PXXP motif abolishes PTTG1 ability in transactivating bFGF. These results suggested that PTTG1 transcription function might be required for cell transforming activity.

\section{PTTG1 transactivating domain, DNA- binding site and its regulation}

PTTG1 is highly hydrophilic and contains a basic N-terminus and an acidic C-terminus. The PTTG1 C-terminal acidic domain suggests that PTTG1 possesses transactivation activity (Ptashne 1988), which was confirmed by Dominguez et al. (1998) in budding yeast and mammalian cells. The C-terminal portion of hPTTG1 activated transcription of his3 and lacZ genes in budding yeast HF7c as well as the luciferase gene in mammalian cells (Dominguez et al. 1998). Murine PTTG1 was also shown to possess transactivating ability, which correlated with its transforming properties (Dominguez et al. 1998). Deletion and mutagenesis analysis in the C-terminal region suggested that $\mathrm{P}^{139}$, $\mathrm{S}^{159}, \mathrm{P}^{157}-\mathrm{P}-\mathrm{S}-\mathrm{P}^{160}$, and $\mathrm{L}^{120}$-D-F-D-L ${ }^{124}$ were critical for PTTG1 transactivating ability (Dominguez et al. 1998). Transient transfection of fusion constructs containing the GAL4 DNA binding domain and different PTTG1 fragments indicated that the transactivation domain is located between amino acids (aa) 119 and 164 (Pei 2000). Pei demonstrated that PTTG1 binds to the c-Myc promoter and identified a PTTG1 DNA-binding domain (aa 61-118) using electromobility shift assay (EMSA; Pei 2001). Further studies suggested that PTTG1 directly binds to the c-Myc promoter at sequences -3 and -5 and between -15 and -20 (relative to transcription starting site). These sites are required for PTTG1 DNA binding, suggesting a GCCGATNNNNNNNNNGCA PTTG1 binding motif (Pei 2001).

PTTG1 contains several regulatory domains. PTTG1 $\mathrm{N}$-terminal SH3 domain-binding motif (located between aa 51 and 54) is important for interaction with mitogen-activated protein kinase (MEK) 1 (Pei 2000). PTTG1-MEK interaction is required to mediate effects of MAPK on PTTG1 transactivation activity. PTTG1 contains a consensus MAPK phosphorylation site (P-X-S/T-P) within the transactivation domain and is phosphorylated by MAPK at $\mathrm{S}^{162}$ (human S165) in vitro, which is critical for PTTG1 transactivation function (Pei 2000). PTTG1 contains a destructive box that is conserved in human, rat, and mouse PTTG1. Also, a KEN box in human or KDN box in mouse and rat are found to be involved in PTTG1 degradation (Zur \& Brandeis 2001), with no evidence to suggest that they are involved in PTTG1 transcription activity regulation. A schematic representation of human PTTG1 protein is displayed in Fig. 1.

\section{PTTG1 interacts with proteins involved in the transcriptional process}

PTTG1 directly binds to several gene promoters and regulates the transcription processes by interacting with other proteins. PTTG1 interacts with $\sim 80$ proteins including several transcription factors such as TBPL1 and ABT1 (Tong et al. 2008). Several proteins that have been thoroughly studied and shown to relate to PTTG1 transcription activity include PBF, p53, Sp1, and USF1 (Fig. 2).

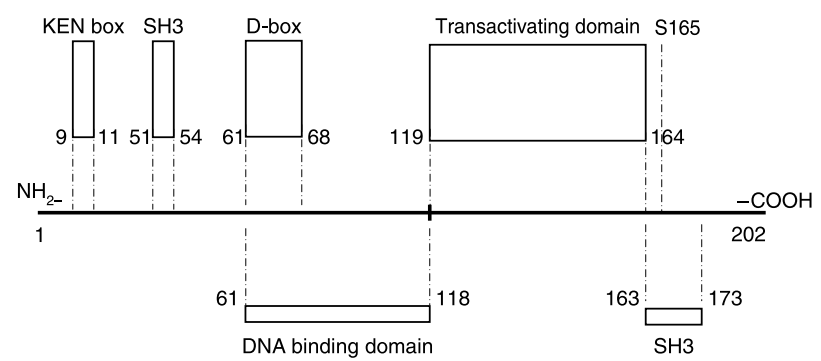

Figure 1 Mammalian PTTG1 contains a basic N-terminal domain and acidic $\mathrm{C}$-terminal domain. The $\mathrm{N}$-terminal domains, including DNA binding domain, KEN-box, D-box, and $\mathrm{SH} 3$ binding domain are mainly regulatory elements. The $\mathrm{C}$-terminus contains a transactivating domain and phosphorylation S165 site. 


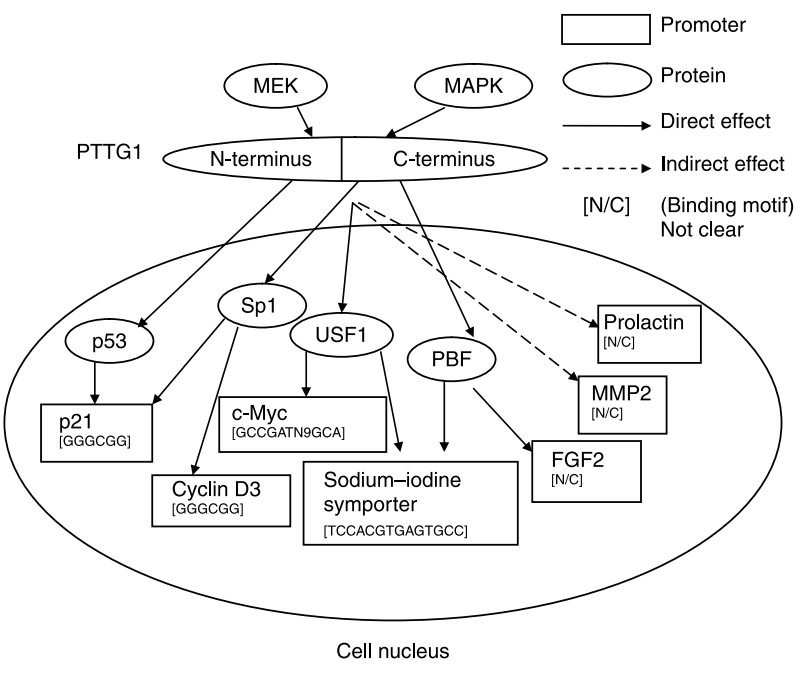

Figure 2 PTTG1 transactivating pathways.

\section{PTTG1 and PBF}

PBF was identified as a PTTG1 interacting protein by using a yeast two-hybrid screen and the PTTG1-PBF interaction was further confirmed by co-immunoprecipitation (Chien \& Pei 2000). PBF contains an open reading frame of 179 aa with a predicted molecular mass of $22 \mathrm{kDa}$. Deletion of 30 aa from the C-terminus abolished interaction between PBF and PTTG, suggesting that $30 \mathrm{C}$-terminal aa are necessary for PBF binding to PTTG1 (Chien \& Pei 2000). The PBF C-terminal 30 aa domain contains a nuclear localization signal (NLS). PBF lacking the NLS domain can no longer bring PTTG1 into the nucleus, suggesting that the domain mediates PTTG1 nuclear translocation. The region between aa 123 and 154 of PTTG1 is essential for the interaction with PBF. PTTG1 and PBF coordinately regulate fibroblast growth factor 2 (FGF2) and sodium-iodine symporter expression (Chien \& Pei 2000, Boelaert et al. 2007).

\section{PTTG1 and p53}

PTTG1 was found to induce p53 expression and apoptosis (Yu et al. 2000), confirmed by Hamid \& Kakar (2004) in MCF-7 and HEK293 cells. PTTG1-p53 interaction was then demonstrated by phage display assay (Bernal et al. 2002). The assay indicated that PTTG1 interacts with a p53 fragment containing residues 109-374. Glutathione S-transferase (GST) pull-down assay indicates that residues (aa 300-374) of p53 and residues (aa 66-99) of PTTG1 are important for mutual interaction. The PTTG1-p53 interaction was confirmed by immunoprecipitation. In gel shift experiments using MCF-7 cell extracts, incubation of cell extracts containing p53 with increasing amounts of purified $6 \times$ His-labeled securin inhibited the formation of the complex. Addition of GST-securinDeltaN (a mutant form of securin lacking the 107 amino-terminal residues and fused to GST) or GST had no effect on complex formation, suggesting that securin specifically binds to p53 and interferes with p53 DNA binding capacity (Bernal et al. 2002). Nuria et al. expressed hPTTG1 using an Escherichia colisystem and investigated the PTTG1-p53 interaction. The results demonstrated that PTTG1 is a natively unfolded protein and there is no direct interaction between unmodified recombinant PTTG1 and p53 in vitro (Sanchez-Puig et al. 2005). Thus, the PTTG1-p53 interaction may require posttranslational modifications.

\section{PTTG1 and Sp1}

Sp1 binding motif is enriched in the PTTG1 targeted genes, suggesting an interaction between PTTG1 and Sp1 (Tong et al. 2007). The PTTG1-Sp1 interaction is validated in both JEG-3 and HCT116 cells using immunoprecipitation. His-tag pull-down assay further demonstrates that PTTG1 N-terminus (aa 1-120) and Sp1 C-terminus (aa 401-785) are required for their physical interactions. EMSA assay shows that intact PTTG1 shifted the Sp1-DNA complex in a dosedependent manner, suggesting a PTTG1-Sp1-DNA complex. PTTG1 is a bipolar protein, with a basic $\mathrm{N}$-terminus and an acidic C-terminus. Intact but not truncated PTTG1 fragments enhanced Sp1 binding, suggesting that the PTTG1 basic N-terminus binds Sp1, whereas its acidic $\mathrm{C}$-terminus may be important for modulating Sp1 activity. The PTTG1-Sp1 interaction has been shown to regulate the cell cycle by transactivating cyclin D3 and p21 (Chesnokova et al. 2005, 2007, Tong et al. 2007).

\section{PTTG1 and USF1}

PTTG1 and USF1 form a complex on the c-Myc promoter (Pei 2001). By performing DNase I footprinting experiments using HeLaS3-PTTG1 cell nuclear extract, a region between -20 and +28 in the $c-M y c$ 5 '-flanking region was protected from DNase I digestion, suggesting that HeLaS3-PTTG1 cell nuclear proteins specifically interact with this DNA sequence (Pei 2001). EMSA assays using the sequence between -20 and +28 as a probe resulted in two mobilityshifted bands. The addition of PTTG1 antibody led to super shift of the upper band, whereas pre-immune serum had no effect, suggesting that PTTG1 is present in the protein complex that interacts with the c-Myc $5^{\prime}$ flanking sequence (Pei 2001). Inclusion of anti-USF1 antibody results in the disappearance of the upper band of the two mobility-shifted bands, suggesting that 
USF1 is a component of the protein complex that interacts with the 48-bp c- $M y c$ sequence. The addition of both anti-PTTG1 and USF1 antibodies resulted in the disappearance of the upper band and the supershifted band, suggesting that USF1 was in the same protein complex with PTTG1 (Pei 2001). Boelaert et al. (2007) found that USF1 site is important for PTTG1 repression of the human sodium-iodine symporter, indicating that PTTG1-USF1 complex may localize on the sodium-iodine symporter promoter.

\section{PTTG1 transcriptional targets}

PTTG1 interacts with several known transcriptional factors and was subsequently found to bind to $\sim 700$ gene promoters (from $\sim 20000$ gene promoters) using a Chromatin immunoprecipitation (ChIP)on-chip assay. About 400 targets were identified and categorized into three major functional groups involved in cell cycle, metabolic control, or signal transduction pathways (Tong et al. 2007), indicating a role for PTTG1 in transcriptional regulation of genes involved in a variety of cellular processes. Among the PTTG1 transcriptional targets, c-Myc, FGF2, cyclin D3, p21, sodium-iodine symporter, prolactin (PRL), and MMP2 are the most investigated and detailed as follows (Fig. 2).

\section{c-Myc}

By coupling a tightly regulated inducible-PTTG1 expression cell system and DNA arrays (investigation of 84 genes), Pei found that c-Myc level (mRNA and protein) was induced within $6 \mathrm{~h}$ of induction of wild-type PTTG1 expression (Pei 2001).There was no change after induction of the transactivation-defective mutant PTTG1 expression, indicating that transcriptional activation function of PTTG1 is required to induce the c-Myc expression. Two constructs containing either $2.5 \mathrm{~kb}$ pairs (HBM-Luc) or $142 \mathrm{bp}$ (XNM-Luc) of c-Myc 5'-flanking region (Pei 2001) fused to the reporter luciferase gene are used to evaluate PTTG1 effects on c-Myc promoter. The luciferase activity of both HBM-Luc and XNM-Luc was increased 2.5-fold when co-transfected with a wild-type PTTG1 expression plasmid, whereas no change was observed when the cells were co-transfected either with the PCMV vector or transactivation-defective PTTG1 mutant. These data suggest that PTTG1 transactivates c-Myc transcription, and the DNA sequences required for PTTG1 transactivation are located within $142 \mathrm{bp}$ of the c-Myc $5^{\prime}$-flanking region. Detailed examination of the effect of PTTG1 on c-Myc expression revealed that PTTG1 activates c-myc transcription in transfected cells and that PTTG1 binds to the c-Myc promoter near the transcription start site (TSS) in a protein complex containing the USF1 (Pei 2001). PTTG1-activated c-Myc expression was confirmed by Hamid \& Kakar (2004) who further identified p53 as a transcriptional target of PTTG1induced c-Myc.

\section{FGF2}

PTTG1 plays an important role in angiogenesis. Thyroid cancers in TR $\beta \mathrm{PV} \cdot \mathrm{PTTG}^{-/-}$transgenic mice have significantly reduced vascular invasion and vessel density, supporting the role of PTTG1 in angiogenesis (Kim et al. 2007b). FGF2 is a well-established target of PTTG1. Both PTTG1 and FGF2 are overexpressed in pituitary (Heaney et al. 1999, Zhang et al. 1999a, McCabe et al. 2003), thyroid (Boelaert et al. 2003), ovarian tumors (Puri et al. 2001), and uterine leiomyoma (Tsai et al. 2005). In vitro experiments have shown FGF2 mRNA induction by PTTG1 overexpression in several cell types, including NIH 3T3 cells (Zhang et al. 1999b, Ishikawa et al. 2001), primary thyroid cells (Boelaert et al. 2004), human fetal neuronal NT2 cells, JEG-3, and MCF-7cells (McCabe et al. 2002). In primary thyroid and PTTG1-null cell lines, transactivation of FGF2 by hPTTG1 was not affected by PTTG1 phosphorylation, but it was dependent on the integrity of C-terminal PXXP motifs (Boelaert et al. 2004). The activity of FGF2 promoter luciferase reporter was not induced by transfecting PTTG1 or PBF expression vector alone, yet its was induced more than threefold by transfecting PTTG1 and PBF together, suggesting that PBF is required for PTTG1 activation of FGF2 transcription (Chien \& Pei 2000).

\section{Sodium-iodine symporter}

The sodium-iodine symporter is responsible for the active and avid uptake of iodine by the thyroid gland. Radioiodine therapy for well-differentiated thyroid tumors relies upon the activity of sodium-iodine symporter. PTTG1 was found to suppress sodiumiodine symporter expression and may be responsible for aggressiveness of the disease (Heaney et al. 2001, Boelaert et al. 2007). A detailed investigation of the mechanism found that PTTG1 overexpression reduces sodium-iodine symporter level; co-transfection of PTTG1 and PBF resulted in an enhanced repression compared with PTTG1 alone. A mutant of PTTG1 (SH3-), which is unable to transactivate FGF2, also repressed sodium-iodine symporter levels (Boelaert et al. 2007). By transfecting sodium-iodine symporter promoter luciferase reporter constructs and PTTG1 into FRTL-5 cells, PTTG1 was unable to repress basal promoter activity (containing the proximal $544 \mathrm{bp}$ ), but significantly reduced activity of the hNUE 
element (containing the upstream enhancer USF1 site), which suggests that PTTG1 signals via the USF1 site on sodium-iodine symporter promoter (Boelaert et al. 2007).

\section{Cyclin D3}

Cyclin D3 was identified as a target of PTTG1 by ChIPon-chip assay and validated by realtime PCR (Tong et al. 2007). ChIP showed that PTTG1 and Sp1 co-localize on the cyclin D3 promoter in both JEG-3 and HCT116 cell lines. Cyclin D3 levels are coordinately regulated by PTTG1 and Sp1 (Tong et al. 2007). Transfection of PTTG1 or Sp1 expression plasmid enhances cyclin D3 level, while transfection of PTTG1 or Sp1 siRNA reduces its expression level. Transfection of PTTG1 plasmid and Spl siRNA reversed the effect of each other, and resulted in a median level of cyclin D3 expression. The PTTG1-regulated cyclin D3 levels in JEG-3 cells are important for G1/S phase transition. PTTG1 siRNA treatment decreased cyclin D3 level, increased G1 and decreased the number of cells in S phase. Co-transfection of PTTG1 plasmid with Sp1 siRNA or PTTG1 siRNA with Spl plasmid reverses the effect of each other on S phase cells (Tong et al. 2007).

\section{p21}

The p21 levels are significantly higher in PTTG1 ${ }^{-/-}$ tissue(Chesnokova et al. 2005), indicating that PTTG1 might suppress p21 expression. Chesnokova et al. (2007) explored the possibility that PTTG1 transcriptionally suppresses p21. Chinese hamster ovary cells were transfected with a murine p21 promoter-luciferase reporter construct and co-transfected with increasing amounts of human WT PTTG1. P21 promoter activity was suppressed dose dependently by the PTTG1 expression plasmid but not by a control plasmid (Chesnokova et al. 2007). ChIP assay further demonstrated that PTTG1 is recruited to the endogenous p21 promoter, spanning the first 120 nucleotides upstream from the transcription start site, but did not bind from the -468 to -765 promoter regions. EMSA assay further confirmed that PTTG1 binds the p21 promoter consensus sequence in the first 120 nucleotides upstream from the transcription start site. PTTG1 antibody dose dependently abolished PTTG-p21 binding, suggesting antibody binding interferes with formation of protein-DNA complexes (Chesnokova et al. 2007).

PTTG1 mediates cell senescence though regulating p21 expression. $\mathrm{Rb}^{+/-} \mathrm{Pttg}^{-/-}$mice have higher p21 levels than $\mathrm{Rb}^{+/-}$, which induce cell senescence and subsequently restrain pituitary tumor development (Chesnokova et al. 2007). p21 deletion restores attenuated pituitary proliferation rates and tumor development in $\mathrm{Rb}^{+/-} \mathrm{Pttg}^{-/-}$mice (Chesnokova et al. 2008). Interestingly, overexpression of PTTG1 in GH3 pituitary cells induces p21 expression and senescence (Chesnokova et al. 2008), suggesting a sophisticated p21 transcriptional regulation.

\section{Prolactin}

hPTTG1, and particularly its C-terminus (aa 147-202), regulates pituitary hormone expression (Horwitz et al. 2003). Pituitary lacto-somatotroph GH3 cells transfected with wild-type PTTG1 C-terminus expression vector decreased ( $\sim 10$-fold) PRL expression, and PRL hormone secretion, compared with cells overexpressing a mutated PTTG1 C-terminus SH3 binding motif (Horwitz et al. 2003). In contrast to PRL, GH mRNA expression, and GH secretion in GH3 cells was enhanced (fourfold; Horwitz et al. 2003). Direct effects of the PTTG1 C-terminus on PRL gene transcription were confirmed using PRL promoter-driven luciferase activity assay (Horwitz et al. 2003). However, there is no evidence showing that PRL is a primary target of PTTG1.

\section{MMP2}

Levels of PTTG1 and MMP2 correlated with angiogenesis and tumor metastasis (Liabakk et al. 1996, Ramaswamy et al. 2003), suggesting a relationship between PTTG1 and MMP2. Malik and Kakar (2006) examined secretion and expression of MMP2 in HEK293 cells transiently or stably transfected with PTTG1 cDNA, and found that transfection of HEK293 cells with PTTG cDNA resulted in enhanced secretion of MMP2. The authors determined MMP2 gene promoter activity and demonstrated a significant ( 11-fold) increase in $M M P 2$ gene promoter activity in cells transfected with PTTG1 cDNA compared with cells transfected with pcDNA3.1 vector (Malik \& Kakar 2006). Thyroid tumors induced in mice by stable expression of PTTG1 showed increased MMP2 expression and activity. MMP2-specific antibody treatment led to decreased cell migration and invasion in vitro. Whether PTTG1 directly binds the MMP2 promoter is not clear.

\section{Future direction}

Accumulating evidence suggests PTTG1 as a biomarker for cancer malignancy and treatment outcome. PTTG1transactivating functions are likely important for the observed phenomenon. PTTG1 regulation of the transcription machinery assembly will be of particular interest. Recent research shows that PTTG1 regulates 
the chromatin structure and histone modification, suggesting that further investigation is needed to elucidate the role of PTTG1 in the regulation of gene transcription at an epigenetic level.

\section{Declaration of interest}

The authors declare that there is no conflict of interest that could be perceived as prejudicing the impartiality of the research reported.

\section{Funding}

This work was supported by NIH Grant CA 75979 (SM), T32 DK007770, and The Doris Factor Molecular Endocrinology Laboratory.

\section{Acknowledgements}

We thank Drs Shlomo Melmed, Run Yu, and Vera Chesnokova for critical discussions in preparing the manuscript.

\section{References}

Bernal JA, Luna R, Espina A, Luzaro I, Ramos-Morales F, Romero F, Arias C, Silva A, Tortolero M \& Pintor-Toro JA 2002 Human securin interacts with p53-mediated transcriptional activity and apoptosis. Nature Genetics 32 306-311.

Boelaert K, McCabe CJ, Tannahill LA, Gittoes NJ, Holder RL, Watkinson JC, Bradwell AR, Sheppard MC \& Franklyn JA 2003 Pituitary tumor transforming gene and fibroblast growth factor-2 expression: potential prognostic indicators in differentiated thyroid cancer. Journal of Clinical Endocrinology and Metabolism 88 2341-2347.

Boelaert K, Yu R, Tannahill LA, Stratford AL, Khanim FL, Eggo MC, Moore JS, Young LS, Gittoes NJL, Franklyn JA et al. 2004 PTTG's C-terminal PXXP motifs modulate critical cellular processes in vitro. Journal of Molecular Endocrinology 33 663-677.

Boelaert K, Smith VE, Stratford AL, Kogai T, Tannahill LA, Watkinson JC, Eggo MC, Franklyn JA \& McCabe CJ 2007 PTTG and PBF repress the human sodium iodide symporter. Oncogene 26 4344-4356.

Chamaon K, Kirches E, Kanakis D, Braeuninger S, Dietzmann K \& Mawrin C 2005 Regulation of the pituitary tumor transforming gene by insulin-like-growth factor-I and insulin differs between malignant and non-neoplastic astrocytes. Biochemical and Biophysical Research Communications 331 86-92.

Chesnokova V, Kovacs K, Castro AV, Zonis S \& Melmed S 2005 Pituitary hypoplasia in $\mathrm{Pttg}^{-/-}$mice is protective for $\mathrm{Rb}^{+/-}$pituitary tumorigenesis. Molecular Endocrinology 19 2371-2379.

Chesnokova V, Zonis S, Rubinek T, Yu R, Ben-Shlomo A, Kovacs K, Wawrowsky K \& Melmed S 2007 Senescence mediates pituitary hypoplasia and restrains pituitary tumor growth. Cancer Research 67 10564-10572.

Chesnokova V, Zonis S, Kovacs K, Ben-Shlomo A, Wawrowsky K, Bannykh S \& Melmed S 2008 p21(Cip1) restrains pituitary tumor growth. PNAS 105 17498-17503.

Chien W \& Pei L 2000 A novel binding factor facilitates nuclear translocation and transcriptional activation function of the pituitary tumor-transforming gene product. Journal of Biological Chemistry 275 19422-19427.
Cho-Rok J, Yoo J, Jang YJ, Kim S, Chu IS, Yeom YI, Choi JY \& Im DS 2006 Adenovirus-mediated transfer of siRNA against PTTG1 inhibits liver cancer cell growth in vitro and in vivo. Hepatology 43 1042-1052.

Dominguez A, Ramos-Morales F, Romero F, Rios RM, Dreyfus F, Tortolero M \& Pintor-Toro JA 1998 hpttg, a human homologue of rat pttg, is overexpressed in hematopoietic neoplasms. Evidence for a transcriptional activation function of hPTTG. Oncogene $\mathbf{1 7}$ 2187-2193.

Hamid T \& Kakar SS 2004 PTTG/securin activates expression of p53 and modulates its function. Molecular Cancer 318.

Heaney AP, Horwitz GA, Wang Z, Singson R \& Melmed S 1999 Early involvement of estrogen-induced pituitary tumor transforming gene and fibroblast growth factor expression in prolactinoma pathogenesis. Nature Medicine 5 1317-1321.

Heaney AP, Singson R, McCabe CJ, Nelson V, Nakashima M \& Melmed S 2000 Expression of pituitary-tumour transforming gene in colorectal tumours. Lancet 355 716-719.

Heaney AP, Nelson V, Fernando M \& Horwitz G 2001 Transforming events in thyroid tumorigenesis and their association with follicular lesions. Journal of Clinical Endocrinology and Metabolism 86 5025-5032.

Hlubek F, Pfeiffer S, Budczies J, Spaderna S, Jung A, Kirchner T \& Brabletz T 2006 Securin (hPTTG1) expression is regulated by betacatenin/TCF in human colorectal carcinoma. British Journal of Cancer 94 1672-1677.

Honda S, Hayashi M, Kobayashi Y, Ishikawa Y, Nakagawa K \& Tsuchiya E 2003 A role for the pituitary tumor-transforming gene in the genesis and progression of non-small cell lung carcinomas. Anticancer Research 23 3775-3782.

Horwitz GA, Miklovsky I, Heaney AP, Ren SG \& Melmed S 2003 Human pituitary tumor-transforming gene (PTTG1) motif suppresses prolactin expression. Molecular Endocrinology 17 600-609.

Hunter JA, Skelly RH, Aylwin SJ, Geddes JF, Evanson J, Besser GM, Monson JP \& Burrin JM 2003 The relationship between pituitary tumour transforming gene (PTTG) expression and in vitro hormone and vascular endothelial growth factor (VEGF) secretion from human pituitary adenomas. European Journal of Endocrinology 148 203-211.

Ishikawa H, Heaney AP, Yu R, Horwitz GA \& Melmed S 2001 Human pituitary tumor-transforming gene induces angiogenesis. Journal of Clinical Endocrinology and Metabolism 86 867-874.

Kakar SS 1999 Molecular cloning, genomic organization, and identification of the promoter for the human pituitary tumor transforming gene (PTTG). Gene 240 317-324.

Kakar SS \& Jennes L 1999 Molecular cloning and characterization of the tumor transforming gene (TUTR1): a novel gene in human tumorigenesis. Cytogenetics and Cell Genetics 84 211-216.

Kakar SS \& Malik MT 2006 Suppression of lung cancer with siRNA targeting PTTG. International Journal of Oncology 29 387-395.

Kim DS, Franklyn JA, Smith VE, Stratford AL, Pemberton HN, Warfield A, Watkinson JC, Ishmail T, Wakelam MJO \& McCabe CJ $2007 a$ Securin induces genetic instability in colorectal cancer by inhibiting double-stranded DNA repair activity. Carcinogenesis $\mathbf{2 8}$ 749-759.

Kim CS, Ying H, Willingham MC \& Cheng SY $2007 b$ The pituitary tumor-transforming gene promotes angiogenesis in a mouse model of follicular thyroid cancer. Carcinogenesis 28 932-939.

Lee IA, Seong C \& Choe IS 1999 Cloning and expression of human cDNA encoding human homologue of pituitary tumor transforming gene. Biochemistry and Molecular Biology International 47 891-897.

Liabakk NB, Talbot I, Smith RA, Wilkinson K \& Balkwill F 1996 Matrix metalloprotease 2 (MMP-2) and matrix metalloprotease 9 (MMP-9) type IV collagenases in colorectal cancer. Cancer Research 56 190-196.

Malik MT \& Kakar SS 2006 Regulation of angiogenesis and invasion by human pituitary tumor transforming gene (PTTG) through increased expression and secretion of matrix metalloproteinase-2 (MMP-2). Molecular Cancer 561. 
McCabe CJ, Boelaert K, Tannahill LA, Heaney AP, Stratford AL, Khaira JS, Hussain S, Sheppard MC, Franklyn JA \& Gittoes NJL 2002 Vascular endothelial growth factor, its receptor KDR/Flk-1, and pituitary tumor transforming gene in pituitary tumors. Journal of Clinical Endocrinology and Metabolism 87 4238-4244.

McCabe CJ, Khaira JS, Boelaert K, Heaney AP, Tannahill LA, Hussain S, Mitchell R, Olliff J, Sheppard MC, Franklyn JA et al. 2003 Expression of pituitary tumour transforming gene (PTTG) and fibroblast growth factor-2 (FGF-2) in human pituitary adenomas: relationships to clinical tumour behaviour. Clinical Endocrinology $\mathbf{5 8}$ $141-150$.

Pei L 2000 Activation of mitogen-activated protein kinase cascade regulates pituitary tumor-transforming gene transactivation function. Journal of Biological Chemistry 275 31191-31198.

Pei L 2001 Identification of c-myc as a down-stream target for pituitary tumor-transforming gene. Journal of Biological Chemistry 276 8484-8491.

Pei L \& Melmed S 1997 Isolation and characterization of a pituitary tumor-transforming gene (PTTG). Molecular Endocrinology 11 433-441.

Ptashne M 1988 How eukaryotic transcriptional activators work. Nature 335 683-689.

Puri R, Tousson A, Chen L \& Kakar SS 2001 Molecular cloning of pituitary tumor transforming gene 1 from ovarian tumors and its expression in tumors. Cancer Letters 163 131-139.

Ramaswamy S, Ross KN, Lander ES \& Golub TR 2003 A molecular signature of metastasis in primary solid tumors. Nature Genetics $\mathbf{3 3}$ 49-54.

Rehfeld N, Geddert H, Atamna A, Rohrbeck A, Garcia G, Kliszewski S, Neukirchen J, Bruns I, Steidl U, Fenk R et al. 2006 The influence of the pituitary tumor transforming gene-1 (PTTG-1) on survival of patients with small cell lung cancer and non-small cell lung cancer. Journal of Carcinogenesis $\mathbf{5} 4$.

Romero F, Multon MC, Ramos-Morales F, Dominguez A, Bernal JA, Pintor-Toro JA \& Tortolero M 2001 Human securin, hPTTG, is associated with $\mathrm{Ku}$ heterodimer, the regulatory subunit of the DNAdependent protein kinase. Nucleic Acids Research 29 1300-1307.

Saez C, Japon MA, Ramos-Morales F, Romero F, Segura DI, Tortolero M \& Pintor-Toro JA $1999 \mathrm{hpttg}$ is over-expressed in pituitary adenomas and other primary epithelial neoplasias. Oncogene 18 5473-5476.

Sanchez-Puig N, Veprintsev DB \& Fersht AR 2005 Human full-length securin is a natively unfolded protein. Protein Science 14 1410-1418.

Shibata Y, Haruki N, Kuwabara Y, Nishiwaki T, Kato J, Shinoda N, Sato A, Kimura M, Koyama H, Toyama T et al. 2002 Expression of PTTG (pituitary tumor transforming gene) in esophageal cancer. Japanese Journal of Clinical Oncology 32 233-237.
Solbach C, Roller M, Fellbaum C, Nicoletti M \& Kaufmann M 2004 PTTG mRNA expression in primary breast cancer: a prognostic marker for lymph node invasion and tumor recurrence. Breast 13 $80-81$.

Tong Y, Tan Y, Zhou C \& Melmed S 2007 Pituitary tumor transforming gene interacts with $\mathrm{Sp} 1$ to modulate $\mathrm{G} 1 / \mathrm{S}$ cell phase transition. Oncogene 26 5596-5605.

Tong Y, Ben-Shlomo A, Zhou C, Wawrowsky K \& Melmed S 2008 Pituitary tumor transforming gene 1 regulates Aurora kinase A activity. Oncogene 27 6385-6395.

Tsai SJ, Lin SJ, Cheng YM, Chen HM \& Wing LY 2005 Expression and functional analysis of pituitary tumor transforming growth factor-1 in uterine leiomyomas. Journal of Clinical Endocrinology and Metabolism 90 3715-3723.

Waizenegger I, Gimenez-Abian JF, Wernic D \& Peters JM 2002 Regulation of human separase by securin binding and autocleavage. Current Biology 12 1368-1378.

Wang Z, Yu R \& Melmed S 2001 Mice lacking pituitary tumor transforming gene show testicular and splenic hypoplasia, thymic hyperplasia, thrombocytopenia, aberrant cell cycle progression, and premature centromere division. Molecular Endocrinology 15 $1870-1879$

Wang Z, Moro E, Kovacs K, Yu R \& Melmed S 2003 Pituitary tumor transforming gene-null male mice exhibit impaired pancreatic beta cell proliferation and diabetes. PNAS 100 3428-3432.

Yu R, Heaney AP, Lu W, Chen J \& Melmed S 2000 Pituitary tumor transforming gene causes aneuploidy and p53-dependent and p53-independent apoptosis. Journal of Biological Chemistry $\mathbf{2 7 5}$ 36502-36505.

Zhang X, Horwitz GA, Heaney AP, Nakashima M, Prezant TR, Bronstein MD \& Melmed S 1999a Pituitary tumor transforming gene (PTTG) expression in pituitary adenomas. Journal of Clinical Endocrinology and Metabolism 84 761-767.

Zhang X, Horwitz GA, Prezant TR, Valentini A, Nakashima M, Bronstein MD \& Melmed S $1999 b$ Structure, expression, and function of human pituitary tumor-transforming gene (PTTG). Molecular Endocrinology 13 156-166.

Zou H, McGarry TJ, Bernal T \& Kirschner MW 1999 Identification of a vertebrate sister-chromatid separation inhibitor involved in transformation and tumorigenesis. Science 285 418-422.

Zur A \& Brandeis M 2001 Securin degradation is mediated by fzy and fzr, and is required for complete chromatid separation but not for cytokinesis. EMBO Journal 20 792-801.

Received in final form 27 March 2009

Accepted 11 May 2009

Made available online as an Accepted Preprint 11 May 2009 